\title{
A rare case of secondary amenorrhea due to closure of perforate transverse vaginal septum
}

\author{
Manjeet Kaur, Bharti Goel, Jasveer Singh
}

\author{
Corresponding author: Dr Manjeet Kaur, Assistant Professor, Dept. of Obstetrics \& Gynaecology, \\ Govt. Medical College \& Hospital, Sector-32, Chandigarh, India; \\ Email - drmanjeetkaur99@gmail.com
}

Distributed under Attribution-Non Commercial - Share Alike 4.0 International (CC BY-NC-SA 4.0)

\begin{abstract}
Perforated transverse vaginal septum (TVS) leading to secondary amenorrhea in unmarried girl is a rare entity. A 20 years old unmarried girl presented to gynaecology OPD with history of amenorrhea since one month and 12 days, pain lower abdomen with swelling since 7 days and difficulty in voiding urine since 2 days. She had history of regular menstrual cycles since the age of 13 years. Local examination revealed pinkish mass bulging through introitus. MRI showed vaginal outlet obstruction with haematocolpos and haematometra. Diagnosis was confirmed and case was successfully managed during examination under anaesthesia. This case highlights the evolution from perforated transverse low vaginal septum with normal and regular menstrual cycles to a complete septum (due to retained menstrual blood and tissue debris) which leads to secondary amenorrhea.
\end{abstract}

Keywords: Transverse vaginal septum, secondary amenorrhea, examination under anaesthesia.

Transverse vaginal septum (TVS) is a rare anomaly of female genital tract with an incidence of 1 in 30000 to 1 in 84000 females. ${ }^{1}$ It is a membrane of fibrous connective tissue with vascular and muscular components which develop from failure of vertical fusion between the vaginal plate and the caudal end of fused mullein ducts. ${ }^{2}$ In $46 \%$ cases septum is present in upper third of vagina, $35 \%$ present in middle third and only $19 \%$ present in lower third of vagina. $^{3}$ TVS can be either complete (imperforated) or incomplete (perforated). Complete TVS usually diagnosed during neonatal period or at the onset of puberty. Incomplete or perforated TVS diagnosed incidentally but may lead to dysmenorrhea, dyspareunia, infertility or hypo menorrhea. Here we report a rare case where 20 year old unmarried girl presents with secondary amenorrhea after normal menses of 7 years due to complete obstruction of TVS which was perforated previously.

\section{Case}

A 20 years old unmarried girl presented to gynaecology OPD with history of amenorrhea since one month and 12 days, pain lower abdomen with swelling since 7 days and difficulty in voiding urine since 2 days. At the age of 13 years she attained menarche. Since then she had regular menstrual cycles of 4-5/30 days with average flow and mild dysmenorrhea. Urine pregnancy test was negative.

On per abdomen examination a mass of 18-20 week size uterus was felt, which was soft in consistency but tender to touch. No guarding or rigidity was present. Local examination showed normal labias. A $3 \mathrm{~cm} \times 2 \mathrm{~cm}$ pinkish mass bulging through introitus with foul smelling brownish discharge was seen. On per rectal examination a soft fluctuating mass filling the whole vagina was felt.

Received: $18^{\text {th }}$ December 2019. Accepted: $27^{\text {th }}$ April 2020.

Kaur M, Goel B, Singh J. A rare case of secondary amenorrhea due to closure of perforate transverse vaginal septum. The New Indian Journal of OBGYN. 2020; 7(1): 108-10. 
Transabdominal ultrasound showed uterus shifted to the right, normal in size and shape with normal bilateral adnexa. Endometrial cavity opened up with fluid in it. Large fluid filled mass present in abdomino-pelvic region. Magnetic resonance imaging (MRI) showed large well defined collection measuring $18 \times 9 \times 10 \mathrm{~cm}^{3}$ in vaginal fornices, endometrial canal and endometrial cavity with obstructive vaginal outlet. Uterus was anteverted, displaced to right and cervix displaced anteriorly. Impression of haematocolpos and hematometra was made due to vaginal outlet obstruction likely to be congenital.

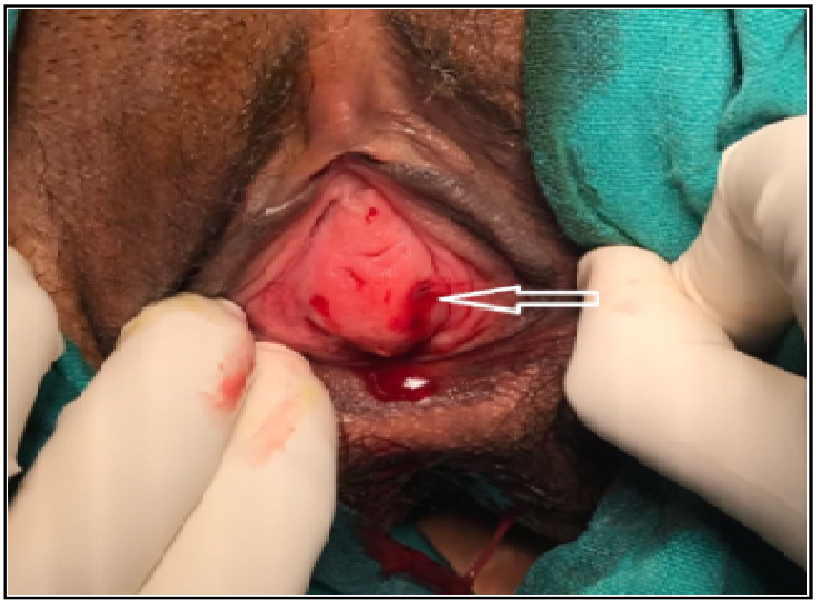

Figure 1: Arrow shows small pin head size opening on the bulge

Examination under general anaesthesia in lithotomy position was planned which showed pinkish bulge around $3 \times 2 \mathrm{~cm}^{2}$ on vestibular area. On labial separation small pin head size opening was seen on the bulge on left side (Figure 1). On pressing the bulge, the opening which was apparently obliterated due to tissue edema, opened up and brownish red discharge came out with free flow. Eventually swelling of abdomen disappeared. It was around $5 \mathrm{~mm}$ thick micro perforated low vaginal septum where perforation was obliterated. Presence of hymen could not be ascertained. Gentle one finger per vaginal examination was done. Beyond septum normal long vagina was present. Normal cervix felt and uterus was normal. No other abnormality was detected by diagnostic laparoscopy.

Septum was excised and adequate opening was made. A mould of appropriate size was kept in the opening to maintain patency for 48 hours. Post operative period was uneventful and she was discharged on $5^{\text {th }}$ postoperative day. After two weeks she was reviewed. Vagina healed well without any complications and next menstrual cycle was normal.

\section{Discussion}

Mullarian duct anomaly incidence is approximately $0.1 \%$ to $3 \%$ and an incidence of TVS found to be 1 in 30000 to 1 in 84000 females. ${ }^{1}$ Effects on critical stage of embryonic growth by abnormal hormone exposure, mutation in genes or arrest in development can result in this anomaly. Most of the septum found at the junction of upper and middle third of vagina. ${ }^{4}$ Low transverse vaginal septum is found less commonly. In complete septum patient usually presents with primary amenorrhea, cyclic pelvic pain or severe dysmenorrhea around the age of menarche due to accumulation of blood above the septum. ${ }^{5}$ An incomplete septum is usually asymptomatic and diagnosed incidentally when patient presents with dyspareunia, infertility or obstructed labour. ${ }^{5}$

In this case 20 year old unmarried girl presents with secondary amenorrhea and swelling in abdomen after normal menses for 7 years where urine pregnancy test was negative. This was a rare presentation of incomplete transverse vaginal septum. On clinical examination diagnosis cannot be made as it presents with pinkish mass bulging through introitus with lower abdominal swelling. Suspicion was made after MRI and it was confirmed only during examination under general anaesthesia when bulge was deeply pressed and obliterated perforation in septum opened up with free flow of collected discharge. MRI has very important role in assessment of suspected vaginal anomalies. ${ }^{6}$ But examination under general anaesthesia has turned out as a gold standard. Surgical excision of the septum was done and post operative period of the patient remained uneventful.

Secondary amenorrhea due to occlusion of perforated low transverse vaginal septum is a rare entity in unmarried girl. This case highlights the transformation of incomplete perforated vaginal septum to complete septum (due to retained menstrual blood and tissue debris) led to secondary amenorrhea.

\section{Conflict of interest: None. Disclaimer: Nil.}

\section{References}

1. Sasikala R, Priyadharshini M, Poomalar GK. Perforated transverse vaginal septum: a rare case report. Int J Reprod Contracept Obstet Gynecol. 2015; 4: 1217-9.

2. Rajanna DK, Chowdareddy N, Kumar JA, Srinivas NS. Transverse Vaginal Septum: A Rare Cause of Primary 
The New Indian Journal of OBGYN. 2020 (July-December); 7(1)

Amenorrhea: Case Report. Sch J App Med Sci. 2014; 2: 762-5.

3. Kanhere A, Nandmer GK, Rai S. Transverse vaginal septum: a rare case presentation as primary infertility. J Evol of Med Dent Sci. 2013; 2: 7847-9.

4. Ventolini G. Vaginal Septum in Adolescents: Clinical Implications. J Genit Syst Disor. 2013; S1

5. Ramarao V, Revathi P, Gupta AD, Mohanrao BR, Saha A. Perforated Transverse Vaginal Septum: report of an unusual case. NJCA. 2013; 2: 221-4.
6. Papaioannou G, Koussidis G, Michala L. Magnetic resonance imaging visualization of a vaginal septum. Fertil Steril. 2011; 96: 1193-4.

\section{Manjeet Kaur ${ }^{1}$, Bharti Goel ${ }^{2}$, Jasveer Singh ${ }^{3}$}

${ }^{1}$ Assistant Professor; ${ }^{2}$ Associate Professor, Dept. of Obstetrics \& Gynaecology, Govt. Medical College \& Hospital, Chandigarh, India; ${ }^{3}$ Associate Professor, Dept. of Anaesthesia \& Intensive Care,

Govt. Medical College \& Hospital, Chandigarh, India 